\title{
CUESTIONES DE TEORÍA EN LOS HISTORIADORES ESPAÑOLES DE LA CIENCIA Y LA TECNOLOGÍA
}

\author{
Siro Villas Tinoco \\ Universidad de Málaga
}

\section{$\underline{R E S U M E N}$}

En este trabajo se analizan algunas aportaciones teóricas que diversos historiadores de la Ciencia y la Tecnología han efectuado en los dos últimos decenios del siglo XX y es continuación de otro estudio similar que contenía las opiniones al respecto efectuadas por filósofos y sociólogos de la Ciencia.

Palabras claves: Historia de la ciencia. Filosofía de la ciencia. Sociología de la ciencia. Teoría de la ciencia.

\section{ABSTRACT}

It is the aim of the present article to analyse some theoretical contributions made by historians of science and technology in the last two decades of the twentieth century. This article is a continuation of a similar study analysing the opinions on the same subject made by philosophers and sociologist of science.

Keywords: History of science. Philosophy of science. Sociology of science. Theory of science

En un artículo recientemente entregado a la imprenta', efectuábamos un análisis de los planteamientos teóricos que algunos filósofos, sociólogos e historiadores de la ciencia (éstos últimos restringidos a quienes de una forma total o parcial habían abordado en sus trabajos temas específicos de Historia Moderna), publicaron en España durante las dos últimas décadas del pasado siglo.

Como síntesis provisional del análisis realizado veníamos a concluir que, en general, la Filosofía de la ciencia, una vez que había trascendido los planteamientos del formalismo lógico extremo ( $y$ también lo que denominan "La concepción heredada"), seguían elucubrando y depurando el concepto de Verdad para

' VILLAS TINOCO, S.: "Reflexiones sobre teoría de la ciencia y la tecnología. (desde la Historia Modema española), colaboración al volumen de Homenaje al profesor Ángel Rodríguez Sánchez. (En prensa). 
aplicarlo a los estudios científicos a través de nuevas teorías filosóficas dotadas de creciente complejidad. Pero el pragmatismo académico, cada vez más exigente con todas las disciplinas científicas, les había llevado a proponer nuevos (o quizá tan sólo renovados) campos de interés, que a veces entraban en estrecha relación ( 0 incluso en colisión intelectual), con los límites acotados por la Sociología para su disciplina.

Asi, los últimos trabajos filosóficos insisten en el racionalismo como el argumento de base, remarcan las diferencias entre la ciencia y la tecnología (rechazando el término "Tecnociencia" acuñado por los sociólogos), al tiempo que argumentan nuevas propuestas para modificar los supuestos axiológicos tradicionales, en el sentido de incorporar a los presupuestos filosóficos para el estudio de la ciencia los principios éticos, utilitarios, evaluativos (sustituyendo el concepto de inconmensurabilidad por el de comunicabilidad) e incluso políticos. En este último sentido han propugnado (sobre unos argumentos de base más sociológicos que filosóficos), el desarrollo de unos proyectos de investigación interdisciplinares que afloren los intereses políticos y económicos subyacentes a toda investigación científica y tecnológica, implementando posteriormente sus resultados cognitivos y sus valores sociales hacia el campo educativo.

Con respecto a las últimas tendencias de la Sociología de la ciencia, parece que la hiperreflexividad teorética finisecular ha desembocado en una vía muerta, acerbamente criticada por cuanto implica una recursividad que termina por invalidar incluso las reflexiones de valía científica contrastada. El camino progresivamente crítico que desde el Programa Fuerte (P.F.), el Programa Empírico del Conocimiento (EPOR) y la Etnometodología, llevó a las posiciones hipercríticas del análisis del discurso, la inflexión reflexiva y la teoría del "Actor-red", habría concluido por vaciar de contenido cualquier reflexión teórica al cuestionar no sólo la capacidad epistemológica del sujeto pensante y la validez de su reflexión, sino incluso la realidad misma del objeto de estudio.

Con respecto a los planteamientos teóricos de los historiadores de la ciencia y aunque no desconocían las aportaciones de los anteriores (algunas de las cuales han prestado coherencia a los estudios puntuales), creíamos que su objeto esencial de estudio no eran ni la Verdad fundamental que validara el trabajo científico, ni las teorias sociales que lo habrian hecho avanzar, sino la evolución de las teorias científicas que en cada momento han intentado explicar la Naturaleza, así como los condicionamientos del entorno social que habrían dinamizado o retardado el trabajo de los hombres de ciencia.

Con respecto a nuestras afirmaciones sobre los dos primeros colectivos aludidos, no tenemos motivos, ni tampoco nueva información específica, que nos 
hagan variar sustantivamente las opiniones expresadas. Pero sí hemos podido allegar diversos trabajos de historiadores de la ciencia que nos permiten profundizar en las conclusiones anteriormente expuestas, matizando algunas de ellas.

Los planteamientos éticos de la ciencia y de la técnica han interesado a los historiadores, que han abordado diferentes aspectos del tema y, por supuesto, con diversas perspectivas, criterios de análisis y conclusiones. Laín Entralgo ${ }^{2}$ describe los problemas, miedos, suspicacias y limitaciones de la técnica, señalando diversos caminos para minimizar sus aspectos negativos, potenciando en cambio los positivos.

Como obra humana que es, la técnica no debería necesitar de ningún tipo de humanización, pero la tendencia del hombre al error y a la desmesura puede convertir una ciencia en in-humana. Laín analiza la tecnología desde tres puntos de vista: como recurso, como peligro y como reto. En el primer caso, la técnica amplía las posibilidades naturales con las que nace el hombre, así como las destrezas adquiridas mediante la educación y el trabajo. En el segundo caso, al menos potencialmente, puede disminuir una parte de las capacidades naturales humanas al eliminar o minimizar su ejercicio habitual. También hace notar que se trata de un potenciador del armamentismo (al fin y al cabo un resultado técnico), recuerda que ningún recurso tecnológico es inocuo y por ello todo artefacto implica peligro potencial. Así, la mecanización deshumanizada limita la libertad, provoca la alienación y erradica la creación filosófica y poética.

Pero en tanto que reto, la misma técnica conlleva la posibilidad de aumentar los recursos, transformándose entonces en un elemento salvador. En principio, la vida es reto y siempre implica la búsqueda de respuestas a los desafios naturales, cuya superación ha elevado la constitución fisica, mental y material de la Humanidad. Un desafio que es al mismo tiempo "exterior" (del mundo) e "interior" (procedente del mismo sujeto).

Las respuestas al reto tecnológico deben proceder, igualmente, de tres planos concatenados. Soluciones "Intelectivas", comprendiendo la esencia de la técnica, su génesis y las profundas transformaciones que opera sobre la misma naturaleza. Respuesta "Imaginativa", sintiendo el gozo de la creatividad técnica, que debe resultar similar al experimentado por la sensibilidad de todo artista creador. $Y$, finalmente, potenciando la base ética, limitando la capacidad tecnológica para producir muerte y destrucción; promoviendo la libertad y aunando en el hombre lo que siente, lo que es y lo que hace.

${ }^{2}$ LAÍN ENTRALGO, P,: "Humanización de la técnica", Revista de Occidente, 184, (1988), 120-135. 
Muy distinto es el tono y las conclusiones de José Manuel Sánchez Ron ${ }^{3}$ que, como historiador en activo, trabaja sobre unos materiales sociales, menos filosóficos, mucho más pragmáticos y que propenden al realismo pesimista. Puede decirse que para este autor la Historia de las ciencias puede ser tomada como base extraordinariamente idónea para establecer unos criterios éticos.

Tres realidades actuales constituyen la base de su personal análisis: la alta valoración social de la ciencia y del papel del científico; la utilidad y la necesidad como valores de la tecnología y la transformación de antiguos valores éticos que eran en sí mismos fines, y que actualmente han sido desvalorizados hasta la consideración de simples medios para conseguir nuevos fines. La relación entre Ética y Ciencia la fundamenta en cinco afirmaciones: 1) El método científico puede conllevar nuevos planteamientos éticos, al mismo tiempo que alumbrar descubrimientos de índole moral. 2) Las investigaciones y las teorías científicas (como, por ejemplo, la Psicología y la Historia) pueden explicar y justificar la existencia de muy distintos sistemas morales. 3) Los logros cientificos y tecnológicos pueden determinar el rango y los límites de las decisiones morales. 4) El avance científico siempre comporta nuevas elecciones y problemas a resolver. 5) El desarrollo de la ciencia puede suministrar lecciones morales y éticas acerca de la convivencia humana.

Los años 60 supusieron, para este autor, el paso de lo abstracto a lo concreto, de la Idea a la Historia de las ideas; pero se trató de un elemento sustancial que no fue adecuadamente aprovechado en todas sus indudables implicaciones éticas. Tras el trauma psicológico que conllevó el bombardeo de Hiroshima y Nagasaki, la opinión acerca del valor y de las responsabilidades morales inherentes a la ciencia y a los científicos se dividieron, pues mientras los críticos la criminalizaban acerbamente, sus panegiristas la exoneraban de toda responsabilidad moral. Esta última, y nada desinteresada, actitud fue la adoptada por quienes él denomina hagiógrafos de la ciencia, que presentan a los científicos como seres idealizados, carismáticos, abstraídos en problemas etéreos y sublimes y dotados de un alto prestigio social que se transmite a todo el grupo (la Nación, el Estado) a la que pertenece.

Las responsabilidades de los científicos en la guerra ya fueron eludidas por Galileo $^{4}$, continuando posteriormente la tendencia autoexoneradora; pero el aná-

\footnotetext{
"SÁNCHEZ RON, J.M.: “La ética del cientifico ¿Conveniencia o convicción?", Sistema, 85, (1988), 45-61.

${ }^{4}$ Ibídem, 50: "Grandes y notables cosas son mías, pero yo sólo puedo servir, a lo más bien, puesto a trabajar por, príncipes, ya que son ellos los que llevan adelante las guerras, edifican y defienden fortalezas y en sus reales distracciones efectúan esos grandes gastos que ni yo ni otros individuos pueden hacer".
} 
lisis histórico sobre la segunda mitad del siglo XIX y acerca del periodo de entreguerras demuestra una vinculación de las grandes figuras de la ciencia con los intereses nacionales, que presenta una facies ambivalente: patriótica y profesional. Las retractaciones intelectuales por motivos éticos o morales, cuando aparecen, suelen ser muy tardías y selectivas, correspondiendo (con alguna excepción significativa por lo raro), a individuos que por su edad o por el status alcanzado, ya están fuera de los sistemas de competencia dependientes del poder político.

Aportando ejemplos irrebatibles, niega rotundamente la existencia de la pretendida Universalidad de la ciencia, analizando el deslizamiento desde la ética del patriotismo a la ética de la conveniencia, con la consagración del valor económico de la ciencia y la posición cambiante de la moral del científico en función de los intereses personales y grupales. Éstos, a su vez, están basados en la alta estima social del científico, en la presión de la competencia y en las exigencias del curriculum ${ }^{5}$. Cuestiona que la guía científica sea un modelo universalmente válido para medir el desarrollo de un pais, analizando las consecuencias del colonialismo cultural y ejemplificando con el caso de la India las implicaciones entre el desarrollismo científico dirigido y el estancamiento social y económico del conjunto de la población.

En las consideraciones finales admite que hay un exceso de sombras en el panorama dibujado, pero reafirma la negra realidad subyacente, al tiempo que niega pretender la exclusión del científico del mundo habitual. Muy por el contrario, entiende que la interacción de éstos con la sociedad circundante puede ser la única vía de salida al conflicto planteado ${ }^{6}$.

Desde 1976 la Asociación Interdisciplinar "José Acosta" venía realizando encuentros anuales, y el de septiembre de 1986 estuvo dedicado al análisis de las relaciones entre ciencia y poder'. Filósofos, teólogos y sociólogos, junto a matemáticos, ingenieros electrónicos, psicólogos, médicos, biólogos, químicos, físicos

\footnotetext{
'Ibidem, 58. "En esta misma línea de argumentación, la de la preocupación del científico por la supervivencia, hay que tener en cuenta un aspecto muy importante en la estructura de las ciencias en estos últimos tiempos: el contrato de investigación. Un elemento muy valorado en el curriculum de un investigador es el número de contratos de investigación que ha conseguido. ¿Tengo que recordar que en estados Unidos, país que marca en muchos sentidos la pauta de lo que se entiende por administración e investigación cientifica, mas del $50 \%$ de la investigación es financiada por el departamento de defensa, con las consecuencias que esto tiene para la investigación científica?

- Ibídem, 60: puede pensarse, por consiguiente, que mi postura es la de arrinconar, aislar, marginar a los científicos. En absoluto. ... Quiero que la ciencia no permanezea en la trastienda, pues es allí donde es más peligrosa. El científico debe participar en el debate social, y los no cientificos están obligados a conocer tanto a la ciencia como a los científicos, ya que sólo así seremos capaces de controlar. Conoeiéndolos, y si es necesario modificándolo, nuestro propio destino".

${ }^{7}$ DOU, A. (Ed.): Ciencia y poder, Madrid, Publicaciones de la Universidad Pontificia de Comillas y Ediciones Mensajero, 1987.
} 
y economistas, afrontaron (cada uno desde su perspectiva específica), la relación entre los descubrimientos científicos y los poderes establecidos, asumiendo una realidad que se iba imponiendo de una forma incontrovertible. La ponencia marco estuvo a cargo del filósofo Augusto Horta $l^{8}$ que pretendía conciliar las visiones, desde dentro y desde fuera, que sobre la ciencia tenían los científicos y la sociedad en general.

Afirma que hay tantas definiciones de ciencia como científicos, temáticas e intereses en juego; analiza el concepto sociológico de "poder" a partir de la visión sociológica de Weber, relacionando ambos términos, ciencia y poder, a partir un análisis actualizado de la de la teoría del Ethos de Merton, con unos efectos absolutamente demoledores, como no podía resultar de otra forma. La ciencia moderna aparece vinculada al poder, porque depende completamente de éste para subsistir, no solo por la vinculación financiera sino mediante otros mecanismos sociológicos algo más sofisticados, como el status que el poder otorga a un científico y niega a otro en función de la utilidad de su investigación y de la docilidad demostrada a las directrices recibidas.

Pero como Saber es poder, la ciencia también adquiere una cierta cuota de poder intrínseco, por cuanto incide en la sociedad a través de la cultura, la salud y la extensión de unos conocimientos que conforman un sistema de valores por los que se rige el ser social. No obstante, parece quedar poca duda de que en la doble dirección de las vinculaciones Ciencia/Poder el predominio es ejercido por el segundo, que incluso puede intervenir activamente en las relaciones de dominación interna establecidas en las comunidades de ciencia institucionalizada, la única vía de investigación factible en el mundo actual.

Las visiones que en sus trabajos ofrecen el físico ${ }^{9}$, el ingeniero ${ }^{10}$ y el psicólogo", no hacen sino confirmar con el estudio de situaciones específicas las afirmaciones de la ponencia marco, siendo muy significativas del momento las aportaciones de Mayor Zaragoza (presentado sólo como biólogo molecular de la Universidad de Madrid) ${ }^{12}$ y del economista Francisco Gómez Camacho ${ }^{13}$, que conciliador el uno y dubitativo el otro, parecen entender que puede (o debc existir) una cierta forma de equilibrio, con una interrelación profunda entre ambos términos del binomio.

\footnotetext{
"HORTAL, A.: "Saberes y Poderes", Ciencia y Poder, cit., 17-41.

"MASAGUER, J. R.: "El poder de la Física: el armamentismo", en Ciencia y Poder, cit., 63-94.

"BRACHO, S.: "Microelectrónica y poder", en Ciencia y Poder, cit., 115-140.

"PINILLOS, J.L.: "La psicología y el poder", en Ciencia y Poder, cit., 175-190.

"MAYOR ZARAGOZA, F:: "Interdependencia entre ciencia y poder político", en Ciencia y Poder, cit., 199-217.

"GÓMEZ CAMACHO, F. "Ciencia y Poder. Una distinción dificil y provocativa", en Ciencia y Poder, cit., 221-224.
} 
Pero las reflexiones teóricas con aristas más duras se producen cuando el historiador de la ciencia se enfrenta a las relaciones de los científicos con el poder, en temas que entroncan con la ética de los comportamientos, porque se refieren a aspectos bélicos cuyas consecuencias tienen trascendencia para millones de seres. Antonio Lafuente ${ }^{14}$, presenta descarnadamente toda la carga política de los comportamientos de grandes y pequeñas figuras de la ciencia.

La ciencia, en tanto que combatiente de plagas y males que afectan a la humanidad constituye una metáfora militante preñada de consecuencias y con mucha mas profundidad de la que aparenta, Actualmente las instalaciones científicas trascienden el típico laboratorio romántico, presentándose como lo que realmente son: inmensas fábricas y gigantescas empresas que albergan colectivos muy jerarquizados y burocráticos, polarizados hacia unos objetivos técnicos, políticos y militares. La politización de la ciencia llegó por el camino de la creciente necesidad de financiación, que trascendieron las posibilidades de los mecenas nobles y cortes de Antiguo régimen, hasta alcanzar el amparo económico de las multinacionales y de las grandes potencias mundiales.

Las restricciones políticas comenzaron en la transmisión de información, calificando los logros científicos como sensibles, reservados o, directamente secretos, llegándose en la primera mitad del siglo XX a la institucionalización del principio de interferencia política en el quehacer del científico. Un control y censura, que un político avisado con Sir Francis Bacon, Ministro de lsabel I de Inglaterra en el siglo XVII, ya preconizó en sus escritos. El famoso Ethos de Merton (escepticismo organizado, universalismo científico, comunitarismo de resultados y desinterés personal), es violado diariamente en el mundo de la ciencia. Múltiples ejemplos, desde el siglo XVII al Proyecto Manhattan, demuestran cómo la realidad política determina el comportamiento científico en un maridaje que se ha consolidado, a pesar de determinadas resistencias (Weber, Marx, Goethe, Nietzsche).

El patriotismo como impulsor y meta del desarrollo científico está ampliamente documentado y justificado socialmente por cuanto que el científico no nace, sino que se hace en una determinada sociedad que le imprime el carácter de su cultura, ideología e intereses dominantes que son, en su mayor parte nacionales. Ejemplos como Arquímedes, Leonardo, Tartaglia y Galileo, entre otros, no pueden ser rebatidos por figuras testimoniales como Descartes y Condorcet, o la neutralidad de la ciencia preconizada por la Royal Society.

"LAFUENTE, A.: "Conflicto de lealtades. Los científicos entre la nación y la república de las letras", Revista de Occidente, 161, (1994), 97-122. 
Pero los casos absolutamente perversos de doctrinas pretendidamente científicas cuya base eran supuestos de un nacionalismo a ultranza (Haekel, Broca, Galton, Lombroso, Jensen y Wilson), no pueden ser confundidos ni entroncados, pese a su común distanciamiento de los planteamientos oficiales, con la Naturphilosophie o ciencia romántica. El necesario abandono del reduccionis$\mathrm{mo}^{15}$, se complementa con las directrices de la presión social y con los intereses dominantes, que son elementos necesarios para comprender la realidad actual en la que la ciencia es comunicación, y ésta se dirige a una sociedad que se sustancia en formas políticas de tipo nacional.

Incluso el nacionalismo puede presentar ciertos ejemplos de victorias de tradiciones científicas emergentes conseguidas cuando el potencial económico y el apoyo político de los estados nacionales ha sido puesto a disposición de un desarrollo científico (casos de Colombia, Brasil, Egipto, Turquía) o cuando el honor nacional ha resultado comprometido o "insultado" por teorías u opiniones despectivos llegadas desde el exterior (Alberto Barton y Carlos Monge). Pero aun así, el vernaculismo presenta múltiples ejemplos de brillantes científicos que han visto su carrera obstaculizada, cuando no interrumpida, por el conflicto entre tradiciones científicas antagónicas. Porque el diálogo entre culturas dispares resulta profundamente difícil y las limitaciones a lo exógeno son impuestas por la prepotencia políticoeconómica del más fuerte ${ }^{16}$.

La metáfora de la "República de las ciencias" resulta ya un argumento insostenible por falso, engañoso e inútil. El proceso de mundialización de la ciencia solo podrá tener sentido y futuro si se plantea en un triple nivel: la expansión a todos los continentes, incluyendo todas las tradiciones de conocimiento y afectando a todas las capas de la población ${ }^{17}$.

\footnotetext{
1s Ibídem, 114: "Nuestra visión del pasado está cambiando e las últimas décadas ... nada podremos comprender sobre la ciencia en el siglo XVIl sin darle la importancia que tuvieron a la hermética, la cábala, la alquimia, la teología, el milenarismo, el vitalismo o la magia. El abandono de viejas teorias reduccionistas nos obliga a pensar en la ciencia como un fenómeno de naturaleza profundamente cultural e idiosincrática.

${ }^{16}$ Ibídem, 121. "Think Yiddish, speak English". Se cuenta en la tradición hebrea que este es el consejo que necesita un hijo cuando parte para instalarse en otro país... ¿Podía ampliarse su sentido y formularse en la forma piensa en vernacular y habla como cientifico? Los argumentos aquí reunidos han intentado darle una oportunidad a la respuesta afirmativa.

${ }^{17}$ Ibídem. "En definitiva, contra lo que fue la opinión generalizada de los partidarios de la teoría de la modernización, nuestra conclusión es que la cultura local, lejos de ser un obstáculo para el desarrollo de la ciencia, es su condición de partida, la fuente de donde deben emanar los estínulos para su desarrollo y el único sustrato en el que puede arraigar. La ciencia, o es un componente de la cultura local o nunca pasará de ser una institución frágil de la que se puede prescindir en momentos de crisis. En definitiva, los científicos deben pensar en hebreo y hablar en inglés".
} 
Otro de los problemas políticos importantes en la Historia de las Ciencias han sido las teorias sobre el centro y las periferias científicas en torno al proceso de la mundialización de las culturas. Como muestra de los diversos posicionamientos traeremos a colación tres estudios, de entre los múltiples que al efecto han visto la luz, el primero de los cuales efectúa una densa síntesis del problema en cuestión ${ }^{\text {l8 }}$.

El modelo propuesto por Basalla para el análisis de la transmisión de la cultura científica ha suscitado las correspondientes controversias, sobre todo bajo la acusación de que más que un modelo explicativo se ha transformado en una prescripción de cómo debieron haber ocurrido los hechos. Además, parece que la conceptualización de la transmisión científica adolece de una visión excesivamente europeocéntrica, lineal y rigidamente secuenciada, que en absoluto es apoyada por los diversos estudios de campo. Lafuente rechaza la consideración de la ciencia como un saber único y universal, si previamente no son tenidas en cuenta las asimetrias del sistema científico, la polarización y la localización de los ejemplos inicialmente aducidos y posibilidad de tomar en cuenta otras variables como los intercambios entre culturas en unos contextos locales perfectamente determinados.

Otro flaco débil de la teoría viene constituido por la diferenciación rígida entre la tradición y la modernidad (que constituye el principal problema de las posiciones difusionistas) y la consideración de que lo tradicional o primitivo resulta, siempre y sin excepción, antitético con la modernidad (base esencial del planteamiento desarrollista), cuando la situación iberoamericana durante el periodo colonial no respondería a ninguno de ambos supuestos de base ${ }^{19}$.

En el desarrollo de la actividad científica de un área se usa una terminología que identifica las estructuras estables a partir de tres criterios básicos: el Geopolítico, el Socioeconómico y el Socioprofesional. Por el primero se conforma la idea de una ciencia periférica escasamente institucionalizada, completamente dominada por una ciencia metropolitana altamente estructurada e institucional, dando como resultado un binomio dominado/Dominador y con la inclusión de términos como Imperialismo cultural y Colonialismo cientifico.

\footnotetext{
"LAFUENTE, A. Y SALA CATALA, I.: "Ciencia mundo colonial: el contexto iberoamericano", en Ciencia colonial en América, Madrid, Alianza, (1992), 13-25.

19 Ibidem, 15: "Nuestro propósito es tratar de identificar las formas características de la organización de la actividad científica en la América colonial. Nos preguntamos por el significado y la tradición de pensamiento en el que se inscriben ciertas expresiones como ciencia periférica, ciencia metropolita$n a$, o ciencia colonial. A continuación trataremos de exponer una estrategia que pennita encontrar los perfiles del modelo que describimos como ciencia colonial. Bien entendido que nuestro propósito no es construir una imagen especular de la realidad colonial iberoamericana, sino un ideal (en el sentido weberiano) que confrontado con los hechos se manifieste predictivo e iluminador.
} 
El segundo criterio conforma una secuencia que parte de un proceso de aculturación científica y conlleva una dependencia tecnológica que coarta las iniciativas locales, cuyas tecnologías inadecuadas llevan al desmantelamiento industrial y cultural. El científico local quedaría alienado y sólo se alcanzaría una posterior ciencia nacional por su vinculación a un nuevo y desartollado sistema productivo. La consideración socioprofesional plantea la oposición entre ciencia marginal y ciencia académica, con un proceso de elitización y/o marginación y una fuga interior de cerebros.

En los estudios de contexto iberoamericano se produjo una aceptación acrítica de un sujeto metahistórico todopoderoso y omnipresente (la Metrópoli, el Imperio, el Centro), sin tener en cuenta la función social que ésta realizó en el campo de las formas simbólicas ${ }^{20}$. Por ello insiste en considerar la existencia de factores endógenos activos, en tanto que no ve suficientemente clara la fase de ciencia metropolitana. Él propone que se parta del estudio del proceso de institucionalización de la actividad científica como un elemento decisivo, así como analizar la ciencia colonial en función de los roles socioprofesionales. Es decir, considerar que hubo tres grupos sociales, que desarrollaban diferentes roles científicos y con diversa capacidad para forzar la institucionalización. El primero sería el Criollo, encargado de difundir y racionalizar los usos técnicos. El segundo el grupo Virreinal, con la función de asesorar y promover el fomento y la innovación. Y finalmente el Metropolitano, especialmente dedicado a la instrucción de las élites rectoras.

Mucho menos teórico y bastante más pesimista se muestra Ten ${ }^{21}$, quien discute la existencia de una ciencia colonial iberoamericana, ni en el siglo XIX. La idealización política del Descubrimiento impuso el mito de la colaboración de las naciones europeas (e incluso de los Estados Unidos), con las repúblicas americanas, que utilizaron sondeos prospectivos referidos a las ciencias puras (menos sensibles a la opinión política que la ciencia aplicada), para averiguar la receptividad al respecto por parte de la élites criollas.

En primer lugar debe distinguirse entre la ciencia de un país y la ciencia en un país, para poder afirmar la existencia de una tradición científica. Pero va mucho más allá y asegura la inexistencia de tal circunstancia en Sudamérica, pues

\footnotetext{
${ }^{70}$ Ibídem, 20: "Hay además un aspecto al que, a nuestro juicio, no se le presta suficiente atención ... la función social integradora y legitimadora que en el universo de las formas simbólicas desempeña el "teatro científico colonial". Para cuyo estudio ... aboga por la elaboración de una poética del poder, no una mecánica"

"1 TEN, A.E.: "Ciencias puras y prestigio nacional. Astronomía colonial y astronomía republicana en Sudamérica", en Mundialización de la ciencia y cultura nacional, Aranjuez - Madrid, Doce calles, 1993, 715-723.
} 
los ejemplos de la cátedra peruana de matemáticas creada en 1657, con un cargo adjunto de cosmógrafo, así como las interesadas informaciones de aparición de publicaciones periódicas locales con anterioridad al siglo XIX, son pura especulación sin existencia efectiva y real, dado que la sociedad criolla no estaba en condiciones de sostener una actividad cientifica ajena por completo a sus intereses económicos. Tampoco pudo haber una astronomía peruana por carecer de una masa crítica de investigadores, que a veces apareció como un espejismo por la actividad de algunas personalidades descollantes ${ }^{22}$.

La tercera visión sobre el ámbito americano, desde la óptica menos conocida del imperio otomano, la suministra Alberto Elena ${ }^{23}$. La identificación del Viejo Mundo exclusivamente con Europa ha marginado durante mucho tiempo las realidades africana y asiática como espacios secundarios, simples paisajes, que no habrían recibido el impacto del Nuevo Mundo. Pero puede y debe hablarse de diversos Viejos Mundos desde las perspectivas social, económica, política, cultural y científica, aunque es verdad que existió escaso intercambio cultural entre ellos, pues los contactos se limitaron a misioneros, diplomáticos, comerciantes y viajeros esporádicos.

Mas el conocimiento turco de la realidad americana esta documentado por los mapas de Piri Reiss, así como por tratados publicados en los siglos XVI y XVII que daban cuenta de algunos viajes al nuevo mundo realizados por musulmanes, pese a las limitaciones al efecto establecidas. Ciertamente que las noticias que más impacto causaron, obviamente por el determinante interés político militar y el enfrentamiento ideológico entre la Cristiandad y el Islam, fue la llegada del numerario que dinamizaba la economía europea y potenciaba el belicismo español, así como la cristianización de las nuevas tierras. Turquía se vio afectada negativamente por la desarticulación de las rutas del comercio tradicional, al tiempo que con su decadencia general se encontró inundada por mercancías, de peor calidad pero más baratas que la producción autóctona.

Tampoco Europa asumió rápidamente la realidad americana, por lo que siguió prestando inicialmente mayor atención al frente europeo. Pero una vez producido el cambio de percepción y mentalidad, el Nuevo Mundo se reveló como una tierra virgen a la que era muy fácil transplantar e imponer la imagen y valo-

\footnotetext{
${ }^{22}$ Ibidem, 721. Se requiere, pues, superadas las necesidades primarias, de lo que llamamos una "masa crítica" de personas, entre las cuales puedan establecerse cadenas de magisterio prolongadas, capaces de sostener instituciones potentes que pongan dichas cadenas al abrigo de los caprichos de la coyuntura. Se requiere, finalmente, de una red de "consumidores" de información que permita la existencia y mantenimiento de publicaciones especializadas, la verdadera "sangre" del organismo entero.

" ELENA, A.: "La configuración de las periferias científicas: Latinoamérica y el mundo islámico", en Mundialización..., cit., 139-146.
} 
res del conquistador, transformándose en una peculiar periferia económica, política, cultural y científica ${ }^{24}$.

En un volumen sobre las expediciones ilustradas ${ }^{25}$, dos antropólogos y un sociólogo aplican teorías de sus especialidades a explicar y justificar las expediciones científicas. Fermin del Pino ${ }^{26}$ propone una comparación cultural antropológica de las motivaciones de las expediciones con elementos de la cultura politica amerindia, como los denominados Plotatch ${ }^{27}$, considerando que los argumentos de base utilitarista, tanto economicista como militar, resultan altamente insatisfactorios si se aplican a la totalidad de los aspectos expedicionarios: gastos, resultados, explotación del éxito, etc. Tampoco los comportamientos subsiguientes: compartir los conocimientos, publicar sin contrapartidas, participación de elementos foráneos como observadores, tienen una justificación racional, mucho menos desde el punto de vista de la ética burguesa que informa nuestro conocimiento actual. Por ello propone introducir un elemento ideológico político que no había sido tenido en cuenta por la historiografía científica.

La explicación heterodoxa aplica el concepto aludido a la documentación interna de las expediciones: memoriales, cartas, diarios, etc. en los cuales los argumentos utilitarios quedan absolutamente subordinados a otros de prestigio de la Monarquía, con la Gloria como término más repetido. El paralelismo con la teoría antropológica resultaría de la consideración de la emulación científica como una parte sustantiva de un creciente prestigio del nacionalismo de estado. La utilización de ese término, a veces entrecomillado para conferirle un sentido específico, es un punto que no encaja con los actuales conocimientos sobre el periodo, al igual que acontece con su análisis de la pugna política y social y sobre

\footnotetext{
${ }^{24}$ lbídem, 146: "Más allá de intercambios económicos, transferencias tecnológicas, prestamos culturales o científicos, el descubrimiento del Nuevo Mundo sirvió a los europeos para restaurar finalmente el orden que ellos ansiaba en el Viejo. Un orden hegemónico que, con algunas fluctuaciones en sus centros de poder, Occidente ya no ha dejado de detentar".

${ }^{25}$ PINO DÍAZ, F. DEL (Coord.): Ciencia y contexto histórico nacional en las expediciones ilustradas a América, Madrid, Departamento de Historia de América "Fernández de Oviedo", Centro Superior de Estudios Históricos, C.S.I.C., 1988.

${ }_{26}$ PINO DÍAZ, F. DEL: "Por una antropología de la ciencia. Las expediciones ilustradas españolas como "plotatch" reales", en Ciencia y contexto..., 173-186,

${ }^{27} \mathrm{El} \mathrm{"plotatch"} \mathrm{es} \mathrm{una} \mathrm{ceremonia} \mathrm{ritual} \mathrm{de} \mathrm{ciertas} \mathrm{tribus} \mathrm{amerindias} \mathrm{en} \mathrm{las} \mathrm{que} \mathrm{el} \mathrm{jefe} \mathrm{reparte} \mathrm{entre} \mathrm{otras}$ tribus, especialmente invitadas para la ocasión, todas las riquezas que su pueblo ha atesorado durante un lapso considerable, lo que si bien supone un despilfarro de biencs económicos, supone una ganancia de prestigio social intertribal que supera con mucho las perdidas materiales. A su vez, el mas poderoso entre los invitados se ve "obligado" a aceptar los regalos y a devolverlos, años mas tarde, en una ceremonia de similares características, lo que le devolverá, disminuido o acrecentado en función de la esplendidez de sus aportaciones, el rango y el status quc habrian resultado simbólicamente rebajados por la obligada aceptación de los regalos iniciales.
} 
el nacimiento del nacionalismo ${ }^{28}$. Concluye que las rivalidades nacionalistas interestatales resultaron un eficaz plotatch que dinamizó la regia munificencia para financiar las expediciones que, finalmente y con un cambio de escenario político, conllevaron la aparición del nacionalismo criollo ${ }^{29}$.

Fernando Monge ${ }^{30}$, discípulo del anterior, reafirma y explicita los argumentos de su maestro, pero aplicando una teoría diferente, debida al antropólogo francés Marcel Mauss ${ }^{31}$. Monge desarrolla su idea en tres estadios que denomina Dar, Recibir y Devolver, el primero de los cuales quedaría formalizado en la petición de la Royal Society al monarca británico para que financiase la expedición de Cook, cuyos diarios recogerían toda la carga de competencia internacional de la empresa. De la segunda fase, la recepción del reto (regalo), habría resultado un efecto vinculante para los demás países, lo que establecería necesariamente una relación de competencia internacional. La tercera fase (devolver el regalo) estaría constituido por la expedición Malaspina como respuesta, con los diarios del marino italoespañol que ponen de manifiesto la competencia y la emulación establecida entre el reto y la respuesta. Habría sido el prestigio nacional el dinamizador de las expediciones científicas que si bien generaron una "alianza para la competencia", fueron gestadas para realzar Internacionalmente el prestigio de la nación hispana.

Dado que los científicos, en tanto que seres sociales, se ven afectados por cuestiones de ideología política y religiosa que, en ocasiones, afectan a su trabajo y se traslucen en sus escritos y manifestaciones, los planteamientos religiosos inherentes a la ciencia han sido objeto de diferentes trabajos.

\footnotetext{
28 Ibídem, 181: "Tal espíritu de emulación tiene en la Europa moderna (desde el renacimiento) un nombre más común: se le llama nacionalismo. Llevaría más espacio justificar el nacimiento del nacionalismo de estado como originado en la Europa del Renacimiento, pero esa emulación entre los monarcas adquiere una nueva dimensión cuando logra que un grupo social importante apoye sus pretensiones. En el siglo XVIII, otra vez, los monarcas españoles logran aglutinar a un sector social en apoyo de su lucha contra la nobleza: este sector basará su ascenso social en la lealtad al monarca y establecerá una cerrada rivalidad mutua con la nobleza y con otros monarcas europeos. Esa es la explicación del ascenso de personas como Campomanes, Floridablanca o José de Gálvez, dentro del reinado de Carlos III.

${ }^{29}$ Ibídem, 186: "La ciencia española del siglo XVIII, originada "socialmente" en la rivalidad nacionalista, termina extinguida por otra rivalidad nacionalista. Aunque en este mismo proceso se generan las nuevas "naciones" hispánicas del Nuevo Mundo.

"MONGE MARTÍNEZ, F.: "La honra nacional en las expediciones de Cook y Malaspina: una visión antropológica", en Ciencia y contexto..., 187-198.

"Ibídem, 191: "Mauss consideraba esta institución del regalo como un "fenómeno social total", es decir, en el que se manifestaban simultáneamente y en diferentes niveles todo tipo de consideraciones de importancia, o claves, de esta sociedad. Esto es, convertía al regalo y al mecanismo de clonación en un "símbolo de la vida social ... a través de la cual podíamos reconocer y analizar las claves del funcionamiento de ese grupo humano. Desarrollo general de la teoría en MAUSS, M. "Ensayo sobre los dones, razón y forma del cambio en las sociedades primitivas", en Sociedad y Antropologia, Madrid, Tecnos, 1979 .
} 
Lain Entralgo $0^{32}$ aborda el tema a partir de una definición de ambos términos, siguiendo posteriormente una línea de pensamiento que desemboca en la "creencia" como último estadio de la investigación y visión final de los científicos. Estima que en toda investigación y en todo razonamiento científico hay una parte pragmática que llega a una verdad evidente; pero, de una forma necesaria, esa evidencia alcanzada experimentalmente esta sustentada en una serie de creencias $^{33}$, generalmente inconscientes ${ }^{34}$, que suponen la plataforma psicológica desde la que parte todo investigador. La creencia ya estaba en el sistema filosófico empirista de Hume y, siguiendo a Ortega, diferencia creencia de idea porque la primera complementa a la segunda, pues mientras una sólo muestra la realidad de las cosas, la otra confiere certidumbre a la realidad.

Siguiendo la secuencia científica: pregunta -respuesta- nueva pregunta y analizando las implicaciones de cada paso, concluye que en el plano de la ciencia estricta siempre se desembocará en unas penúltimas preguntas, pues posteriormente, al profundizar en la realidad, se entrará en el campo filosófico. Pero tampoco entonces podrá alcanzar las verdaderas ultimas preguntas ${ }^{35}$ y en tales casos la ciencia se hace religión secularizada, promoviendo la confianza ilimitada en la ciencia que se produjo en la segunda mitad del siglo XIX y que desapareció con el escepticismo imperante en el $\mathrm{XX}^{36}$.

La actitud última del científico se puede manifestar bajo cuatro opciones: la Desesperación, con ejemplos bien conocidos como los de Leopardi o Sartre; la Metáfora, que utiliza la alusión y la poesía para orientar hacia el misterio; el Agnosticismo, según el cual puede haber algo último, pero en todo caso caerá fuera de la comprensión humana; y la Creencia, que él define como la entrega personal con la inteligencia y con el corazón.

\footnotetext{
"2 LAÍN ENTRALGO, P. “Ciencia y creencia”, Revista de Occidente, 103, 1989, 85-105.

"Ibidem, 86: ". . la creencia se presta a la realidad de algo que no puede ser conocido con evidencia, que no puede ser objeto de conocimiento científico. Creencia es, pues, la admisión por asentimiento de algo que racional o cientificamente no puede ser demostrado.

${ }^{14}$ Ibidem, 87: "Nuestro químico [el sujeto que efectúa la experimentación del ejemplo] se movía y actuaba sobre la inconsciente creencia - en modo alguno reducible a evidencia-. En Ia, para él, no visible integridad de su laboratorio, en la sólo posible resistencia de sus tubos de ensayo y en la nada cierta pervivencia de su organismo".

"Ibidem, 93: "Nuestro problema es: para el hombre de ciencia, en cuanto tal hombre de ciencia (Hay preguntas últimas y puede haber últimas respuestas?

${ }^{36} \mathrm{Ibidem}, 95-96$. "Lo que ha hecho crisis no ha // sido la ciencia en cuanto tal, sino la convicción de que el saber científico es por sí mismo capaz de dar al hombre una certidumbre absoluta y última acerca de lo que en sí misma es la realidad".
} 
Diferente es el pensamiento de Sánchez Ron ${ }^{37}$, que sitúa las cuestiones ideológicas en el plano de la religiosidad institucional más que en el de las creencias personales. Los descubrimientos cosmológicos en los comienzos del siglo $\mathrm{XX}$ mostraban un Universo más extenso que nuestra galaxia, así como los avances radiológicos de la década de los 50 añadieron una serie de elementos nuevos: quásares, púlsares, estrellas enanas blancas y gigantes rojas, etc. En su conjunto dieron lugar a diferentes teorías: Universo abierto o pulsante; micro y macro Cosmos; partículas elementales; Interacción gravitacional, etc., todas la cuales trataban de explicar los Primeros instantes del Universo, un tema muy fácil de entroncar en el plano ideológico con el problema de la Creación.

Dos teorías, entre otras muchas anteriores y posteriores, han obtenido la primacía en la consideración científica. La del Big Bang, que implica una expansión a partir de la nada y la del Estado estable, que no precisa un inicio ni un final del Cosmos y que se basa en el Principio cosmológico perfecto, que evita entrar en la consideración de la creación del Universo. La primera citada estaba mucho más cercana a la visión católica del Universo, por lo cual fue defendida por Milne y Whittaker, siendo apoyada más o menos directamente por el Vaticano. Previamente (en 1727), la investigación del jesuita Lemaître, ya avanzaba la idea de un universo expansivo, que posteriormente se sustanció en el concepto de un átomo primitivo, que al estallar originaría el Universo.

La cuestión ideológica de fondo radica en la posibilidad, o imposibilidad, de que una u otra puedan justificar o apoyar unos planteamientos religiosos, pues la teoría del Big Bang, no ya desde un punto de vista filosófico sino desde el sentido común, tanto puede aprobar una opción como la contraria ${ }^{38}$. Según Barrow, cualquiera que acepte la existencia primigenia de un Dios al que no se le deba asociar una causa, podría y debería aceptar también la idea de que el Universo puede ser, él en sí mismo, una causa sin causa ${ }^{39}$.

Los temas concernientes a la divulgación de la ciencia y al rol de los científicos ha sido abordado por la moderna Sociología a partir del Programa Fuerte y los estudios de Etnociencia. Lafuente ${ }^{40}$, como historiador de la ciencia, ofrece una amplia síntesis que presentamos sus elementos más sustantivos.

\footnotetext{
"SÁNCHEZ RON, J.M.: "La creación y las dimensiones", Claves de la Razón Práctica, 1, (1990), 65-68.

"Ibídem, 67: En mi opinión, tal interés no es sino una manifestación de las esperanzas aireadas por Pio XII. ... ¿En base a que, por ejemplo, se puede tomar la teoría del Big Bang como una prueba de la existencia de Dios? Habitualmente el argumento que se emplea es que todo debe tener una causa y que, por consiguiente debe de existir una eausa para el Universo -especialmente habida cuenta de que "es creado" (El Big Bang)- que sea otra que el propio Universo".

3v lbidem,

"LAFUENTE, A.: "Los cientificos ante su imagen", Claves de la Razón Práctica, 67, (1996), 48-55.
} 
La ciencia es ubicua y opaca y ha sido postulada como legitimadora de unas soluciones técnicas que, mayoritariamente, se reciben como beneficiosas para el desarrollo de la humanidad. Pero, en paralelo con ello, resulta evidente la progresiva decadencia de las grandes expectativas depositadas en que la divulgación científica focalizaría del interés de las masas hacia un tema difícil de comprender por su complejidad intrínseca y por el lenguaje especializado en que se formulaban sus teorías.

Las complejas y cambiantes relaciones entre el científico y el público no tienen nada de naturales, habiendo sido históricamente construidas debido a motivaciones cambiantes, siempre en beneficio de los primeros. Desde las sesiones experimentales de la Royal Society, durante el siglo XVII, el público asistente era testigo -y daba fe-, del progreso científico y del trabajo de los investigadores, validando su esfuerzo ante el conjunto de la sociedad. En la centuria posterior, por la especialización y complejidad de los nuevos saberes, la tarea de legitimar al investigador correspondió a otros colegas, que en pié de igualdad entenderían la abstrusas cuestiones que, ni siquiera vulgarizándolas, podrían ser captadas por la masa popular. La sustitución del patronazgo por la profesionalización parecía obviar la necesidad de una justificación social de los científicos, porque su rendimiento económico sería la prueba fehaciente de su utilidad. Además, el distanciamiento del público tenía lugar en un momento en que la vulgarización científica en forma novelada sustituiría ventajosamente las practicas demostrativas por la recreación imaginativa, dejando palmariamente claro que la ciencia era cosa de expertos y que nada podría, ni debería, ser cambiado al respecto, porque el científico prometía bienestar pero exigía un crédito moral y una total autonomía para realizar su trascendental cometido ${ }^{41}$.

Pero la otra facies de la vulgarización implica que el público consolidaba un espacio de poder en el campo científico, lo que confería a los neófitos (au1 sin ellos saberlo), un cierto protagonismo en tanto que sujetos pasivos de un combate que se desarrollaba a sus espaldas, pues la lucha por la supremacía interna pasaba por conseguir el favor popular para dirimir, fuera del campo de la estricta controversia científica, el triunfo de unas teorías sobre otras.

El público de la ciencia conforma sus imágenes en torno a dos modelos básicos: el científico prometeico y el fáustico, unos estereotipos forjados por los

\footnotetext{
*l lbídem, 50: "Mientras los científico aseguraban así las fronteras del campo de acción social del que se consideraban propietarios en exclusiva, la población accedía a concederles amplios márgenes de autonomia a cambio de la promesa de progreso y bienestar social. El problema con nuestra historiografia ha sido, en este como en otros campos, su inveterada vocación apologética y su insuperable visión teleológica del progreso; es decir su capacidad para presentarnos el pasado como un antecedente necesario d nuestro presente, como el escenario entre las sombras y la luz, entre vencedores y vencidos entre la república de las Letras y la república civil, un combate nunca terminado pero siempre victorioso, de los sabios contra los ignorantes.
} 
medios de comunicación de masas que a partir de entonces se consolidaban como el único puente mediático que alimenta la imaginación y el conocimiento superficial del pueblo acerca de los adelantos de la ciencia. En ese primer contexto se inscriben las obras optimistas de Verne, Shelley y Melville, críticos con el individualismo fáustico y tendentes al utopismo prometeico, cuyas obras anteceden el pesimismo de Wells, Morris, Lang y Huxley, los primeros en desconfiar seriamente del poder creciente de la ciencia.

El impacto científico en la mentalidad colectiva se sustancia en unas relaciones complejas y cambiantes, en las que predomina el estereotipo del sabio héroe, demiurgo, singular, distinto y dominador de saberes exotéricos para el común de los mortales. A veces también aparece la contrafigura del científico fáustico, loco, dominado por unas fuerzas que imprudentemente ha convocado, pero en ambos estereotipos su fígura humana es distante, está poco definida y carece de atractivos masculinos, que en realidad no precisa porque se mueve en un aislamiento esotérico en el que las pasiones humanas no tienen cabida ${ }^{42}$.

Aun aceptando que el laboratorio, el locus privilegiado del científico, suponga la quintaesencia de sus valores, su interés social implica la necesidad de estudiarlo porque es el ámbito en el que se produce la dialéctica entre el saber y el poder y, en consecuencia, resulta de un alto interés para la sociedad que lo financia. Los estudios sobre la vida del laboratorio fueron propugnados por los sociólogos de la ciencia y tienen un lejano precedente en la conocida obra El Principe, de Maquiavelo, que es un estudio del poder desde dentro; del lugar mismo en el que se conciben todas las maquinaciones que posibilitan y facilitan el gobierno de los pueblos. Como es natural al tratarse de una lucha de poder (o por el poder), los resultados han desmitificado la bucólica imagen del lugar feliz y reposado ${ }^{43}$. Por el contrario, muestran el campo de batalla de una pugna cientifica en el que la infradeterminación de las propias microteorias fuerza a pactar, interna y externamente, para obtener el triunfo o el fracaso ${ }^{44}$.

\footnotetext{
${ }^{42}$ Ibídem, 53: "Turaine propuso la tesis de que cada momento histórico ha tenido un locus, privilegiado donde se han creado, recreado y exportado al exterior, los valores que han cohesionado o modificado el sistema social. asi, al monasterio medieval siguió el palacio renacentísta, el complejo industrial decimonónico y por fïn, en nuestra época, el laboratorio".

${ }^{41}$ Ibídem, 54. "El laboratorio no es un espacio armónico y ordenado. Al contrario, es un universo caótico, plagado de secretos intereses y grupos en competición. Todo conspira para que se produzca la publicación rápida y, por tanto, no hay holgura de tiempo: los experimentos tienen que funcionar y siempre apremian los plazos".

${ }^{44} \mathrm{lbidem}$. "Todas las precauciones son pocas: hay que medir las palabras y mediante las citas de la obra de otros colegas, enrolarse en un colegio invisible internacional en el que se contribuye a consolidar en la misma medida en que éste, previsiblemente, puede sostenerte. Na hay garantías de éxito, no todo el mundo puede llegar a ser famoso y reconocido, pero es más fácil cuanto más próximo se esté al centro del colegio invisible. En todo caso si cabe vislumbrar una estrategia útil: ligar la práctica de tu laboratorio a la práctica de los laboratorios donde está el público para quien se escribe".
} 
La capacidad de comunicar y negociar se han convertido en condiciones inherentes al científico moderno (un entrepeneur como Schumpeter llamó a los aventureros que en el XIX concitaban en sí mismos la visión del innovador y la audacia del hombre de empresa), dominador de unos espacios de poder que trascienden con mucho los límites de sus centros de trabajo para incardinarse en una red de intereses entrecruzados a nivel internacional. Aislar, o aislarse, de las masas no significa ignorarlas; muy por el contrario es imprescindible convertirlas a la fe de la ciencia (naturalmente de su ciencia), y utilizarlas como palancas para mover los resortes del poder ${ }^{45}$. Más esa necesidad de una masa adicta es lo que confiere al pueblo una cuota de poder en las decisiones cientificas que, trascendiendo el campo de los intereses personales, tienen una importancia esencial en el devenir del conjunto social.

La limitación de espacio inherente a toda publicación científica no nos permite abordar otros muchos trabajos que también inciden en los problemas planteados $^{46}$. Algunos temas, en especial los referentes a la estricta Filosofía de la ciencia, han sido preteridos en beneficio de los que hemos considerado representativos de las tendencias más significativas en los momentos actuales.

\footnotetext{
${ }^{45}$ Ibídem, 55: “... considerar los textos concebidos en el laboratorio como integrantes en su totalidad de un mismo proceso de comunicación según tres reces diferenciadas: las de corresponsabilidad entre colegas, las de patronazgo con las agencias financiadoras y las de popularización con los públicos ${ }^{46}$ BUJOSA HOMAR, F: "El concepto de ciencia en la obra de Pedro Laín Entralgo", Arbor, 143, (1992), 201-213. CAPEL, H.: "Sobre ciencia hispana, ciencia criolla y otras ciencias europeas", Asciepio, 39, (1987-2), 317 - 336. ELENA, A. Y ORDÓNEZ, J.: "De la Revolución Científica a la Revolución Industrial: la dinensión tecnológica", Hispania, 56, 193, (1996), 541-564. ID.: "Ciencia y técnica en un contexto periférico: el mundo islámico", Arbor, 142, (558-559-560), (1992), 217-231. ID.: "La ciencia en los salones, o de cómo al punto ...", Arbor, 144, (565), (1993), 51-63. ID.: "El ángel inoculador", Arbor, 145, (569), (1993), 17-37. ID.: "De Meles a Terninator", Arbor, 145, (569), (1993), 9-16. ID:: “iRevolución en Geologia?", Arbor, 124, (480), (1986), 9-45. ID.: "Utopías cientificas del siglo XVI", Lhul, 9, (16-17), (1986), 65-80. ESTEBAN PIÑERO, M.: "Ciencia y técnica, fuente y guía para la investigación sobre la ciencia y la técnica en el Siglo de oro", Arbor, 153, (604 605), 1996, 37-56. LAFUENTE, A. Y PIMENTEL, J.: "Los imperarivos de la Objetividad", Revista de Occidente, 210, (1998), 75-92. LAÍN ENTRALGO, P.: "Tres reflexiones éticas", lsegoria, 13, (1996), 99-117. ID.: "Respuesta a la técnica", Arbor, 120, (469) (1985), 13-34. PÉREZ SEDEÑO, E. "And the Winner is", Endoxa, 12-2, (1995), 697-722. ID.: "No tan bestias", Arbor, 144, (565), (1993), 17-29. 1D.: "Mujer y ciencia: una perspectiva", Arbor, 144, (565), (1993), 9-16. ID.: "Filosofia de la ciencia y la religión", Revista de Occidente, (18) (1977), 56-71. PESET, J.L.: "Ciencia y poder", Asclepio, 40, (2), (1988), 163-177. PUERTO SARMIENTO, F. J. "Un clásico contemporáneo", Arbor, 153, (604605), (1996), 23-35. RIERA TUEBOLS, S.: "Experimentalismo e llustración", Afers, 30, (1998), 339347. ID.: "Más allá de la ciencia y de la técnica", Vela Mayor: Revista Ancya de Edutcación, 3, (1994), 65-71. ID.: "De galileo al Voyayer", $L$ 'avenç, 48, 1982, 35-38. SALA CATALÁ, J.: "La explicación biológica", Lhll, 4, (6-7), (1981), 163-169. SÁNCHEZ RON, J.M.: "El Liniverso", Revista de Occidente, 207, (1998), 5-18. ID.: "Usos y abusos", Enseñanza de las ciencias, 6, (2), (1988), $179-$ 188. ID.: "Fisica y Filosofia", Theoria, 2, (1985), 439-459. Ortega, M.: "La naturaleza de la ciencia", Tarbiya, 24, (2000), 518-527.
} 
Las matizaciones a las que nos referíamos en el encabezamiento de este artículo pueden sintetizarse en los siguientes aspectos. Las reflexiones de los historiadores de la ciencia presentan, lógicamente, una mayor carga de experiencia y conocimiento de las coyunturas, contrastando las teorías con diversos estudios de base que permiten validarlas o refutarlas sobre una base empírica considerable. Hay dos consideraciones que, estimamos, merece la pena destacar. De forma progresiva, la reflexiones teóricas se van cargando de pesimismo y la fe en la Ciencia y la confianza en los científicos es cuestionada cada vez con mayor intensidad, lo que se manifiesta abiertamente en la duda generalizada acerca de que la validación de las teorías y la elección entre opciones y variables se efectúen mediante pruebas y contrastes de base exclusiva o prioritariamente científica. En otro sentido, la reflexión en forma de ensayo (un estilo generalmente anterior en el tiempo), muestra una mayor tendencia al optimismo y la confianza en la perfectibilidad del ser humano. Por el contrario, en la actualidad los condicionamientos sociales sobre la Ciencia hacen que el pesimismo de Hobbes predomine sobre la confianza ilustrada de Condorcet.

Contrariamente a la visión de los filósofos, la búsqueda de los principios está bastante diluida, quizá porque el interés del historiador por la Verdad en un sentido abstracto, filosófico, absoluto, hace tiempo que fue sustituido por el intento de delimitar verdades operativas y procesuales, que en último término son únicamente vcrdades relativas. No obstante, el indudable interés por los planteamientos éticos se halla en pie de igualdad entre ambos colectivos.

Las teorías sociológicas han merecido la atención de los historiadores en el mismo sentido en que sus creadores les solicitaban: para ser validadas a través de su contraste con la experiencia histórica. En tal sentido, y por lo que afecta a la Edad Moderna, pocas entre las nuevas tendencias tienen un fácil encaje o validación, quizá porque al haber sido gestadas en un contexto social muy diferente y por estructuras mentales comparativamente evolucionadas, la realidad histórica pretérita carece de elementos que permitan una comparación adecuada. 